\title{
Effect of weave type on abrasive strength of cotton fiber
}

\author{
Mehreen Ijaz $^{1 *}$, Muhammad Maqsood ${ }^{2}$ and Namood-e-Sahar ${ }^{1}$ \\ 1. Department of Home Economics, Lahore College for Women University-Pakistan \\ 2. Grey Marketing, Nishat Mills Pvt. Ltd-Pakistan \\ *Corresponding author's email: mehreenijaz@hotmail.com \\ Citation
}

Mehreen Ijaz, Muhammad Maqsood and Namood-e-Sahar. Effect of weave type on abrasive strength of cotton fiber. Pure and Applied Biology. Vol. 9, Issue 3, pp1807-1812. http://dx.doi.org/10.19045/bspab.2020.90192

\begin{tabular}{llll}
\hline \hline Received: 17/02/2020 & Revised: 25/04/2020 & Accepted: 28/04/2020 & Online First: 30/04/2020 \\
\hline
\end{tabular}

\section{Abstract}

Abrasion has a strong relationship with the overall performance of fabrics. There are number of factors that have an impact of abrasive strength of textile materials. These include type of fiber, nature of yarn, yarn number, weave structure and type, number of interlacing in warp and weft. Abraded fabrics look bad in appearance and they no longer can be able to give required service for which they are intended to provide. This study aimed at determining the effect of various weave types on abrasive strength of cotton fabric. The fabric was manufactured through ring spinning technique with three weave structures such as plain, twill and satin. Manufactured fabrics were evaluated for their abrasive strength by following ASTM 4966 test standard. These were evaluated at various laundering intervals such as at $0,5,10$ and 15 . The mass loss in percentage of was then calculated. It was concluded that plain weave structure was the most strongest in terms of its abrasive strength followed by twill and satin. Small floats helped to make the fabric hold components yarns together and provide cohesion to the finished product. It is important for the textile manufacturers and fashion designers to look for various weave structures and their impact on products in order to make creative variations to attract their customers.

Keywords: Abrasion; Plain; Satin; Twill; Washing Cycles; Weave

\section{Introduction}

The performance behavior of fabrics largely depends on many technical aspects that must be planned and designed during manufacturing phase [1]. Weaving structure of finished fabrics is one of the main causes of its high or low performance, as it has a strong relationship with an overall performance. Moreover, some other factors have also an indirect effect on the serviceability of end product such as weaving environment, temperature, humidity, yarn density, yarn number, interlacing pattern and yarn tension etc. [2]. Woven fabrics are made by interlacing two sets of yarns, one running in the lengthwise direction known as warp or ends and another running crosswise is known as weft or picks [3]. Fibers content, yarn structure and weave type are some of the important key factors that dictate the performance of an end product. They affect many physical and chemical properties of fabrics [4].

Woven fabrics are supposed to provide strength to the material and are considered long lasting as compared to any other manufacturing technique. Their performance behavior in terms of strength, flexibility, extensibility and durability is depended on the way of interlacing of yarns in warp and weft directions, thread count per inch, type of twist and yarn count [5]. Woven materials are more versatile due to their unique construction. They can have 
variation in their appearance through change in number of upward and downward harnesses. There are many weave structures which have an effect on the external forces applied on the end product creating change in appearance and shape. The weaving structure also affects the mechanical behavior of products such as the way of load, stress and strain curve, percentage of extension and applied force etc. [6].

Fabrics undergo many wear and tear conditions with the passage of time. The resistance against abrasion is a very complex phenomenon. It has a strong relationship with the durability and strength of fabrics. It is of great importance in apparel, upholstery and technical textiles. [7]. Abrasion is the rupture of component fibers, yarns and fabrics due to their rubbing over some other surface. This deteriorates an overall performance of fabrics. It also differs from individual to individual due to their style of using and caring the garments [8]. It may be caused due to simple rubbing, during wear and tear conditions and while laundering methods [9]. Abrasion not only creates change in surface appearance but also affects the physical properties of abraded fabrics such as thickness loss, improved air permeability, yarn hairiness etc. [10].
Pilling caused by rubbing is always a problem for woven and knitted fabrics. It displaces the fibers or yarns from their original place and creates small bundles that strongly anchor to the fabric surface. Abrasion can completely damage the fabric by tearing a yarn or thread, decreasing its thickness, changing color and even making a hole in the fabric. This problem aggravates more in filament yarns especially made from synthetic fibers [11, 12]. The harshness caused by abrasion is usually based on particle size, its shape, force applied and frequency of rubbing against any abrader [13]. One state of abrasion occurs where solid particles are able to move their place from one area to another and damage the surface. Whereas, another state is caused where particles are roll away from the surface of substrate [12].

\section{Materials and methods}

Ring spun yarns were produced to make woven fabrics with cotton fibers. Three types of weaves such as plain, twill and satin were selected to manufacture these fabrics. The manufacturing process was done at Nishat Mills Private Limited. Construction parameters of manufactured fabrics are given in (Table 1). These fabrics were then tested for their abrasive strength at $0,5,10$ and 15 washing intervals.

Table 1. Construction parameters of manufactured fabrics

\begin{tabular}{|c|c|c|c|c|}
\hline Weave type & Fabrics Mass & $\begin{array}{c}\text { Thread Count } \\
\text { (warp / weft) }\end{array}$ & $\begin{array}{c}\text { Yarn Linear density } \\
\text { (warp) Tex system }\end{array}$ & $\begin{array}{c}\text { Yarn Linear density } \\
\text { (weft) Tex system }\end{array}$ \\
\hline Plain & 115 & $70 \times 75$ & 10.25 & 11.25 \\
\hline Twill & 107 & $83 \times 91$ & 12.25 & 12.05 \\
\hline Satin & 119 & $80 \times 83$ & 10.68 & 11.59 \\
\hline
\end{tabular}

American Society for Testing and Materials (ASTM D 4966) test procedure was followed to measure abrasion resistance of fabrics through Martindale tester [14]. Testing was conducted in a standard atmosphere with $21{ }^{\circ} \mathrm{C}$ temperature and $65 \%$ relative humidity [15]. A specimen from each group of samples was randomly taken in order to avoid any sort of biasness. In this way, every area in the prepared fabrics had an equal chance of selected as specimen for testing. It was made sure that no sample was collected from or near the selvedge area as its properties varies from the rest of the material. Creases and wrinkles were also avoided while extracting samples.

A circular specimen (approximately 1.5 inches) was taken so that all warp and weft threads can be added into the specimen. Each specimen was placed with an upside down in a holder. A piece of felt was used 
as an abradant. A weight of $9 \mathrm{kPa}$ was added to the machine. A predetermined number of rubbing cycles was selected and entered into the machine. The machine was stopped at each rubbing intervals of 1000, 2000 and 3000 cycles in order to evaluate the percentage of loss in thickness of tested materials. Mass loss before and after rubbing cycles was compared in order to determine the abrasive strength of each tested sample.

The samples were laundered by following recommendations given by American Association of Textile Chemists and Colorists (AATCC) Monograph M6 [16]. A standard detergent weighing 0.1 grams per liter was put in the front loading machine to wash all the samples. Agitation speed was kept at 45 revolutions per minute. Laundering temperature was $54^{\circ} \mathrm{C}$ for 11 minutes. Washing cycle was followed by rinsing and spinning cycles. Tumble drying was made at $65^{\circ} \mathrm{C}$ for approximately 60 minutes. A total of 15 laundering cycles were given to all samples. Samples were labeled after every five washes and placed in a separate bag with tag 5-washes. Remaining samples were again washed for five times and marked as 10-washes. The process continued till 15 washing cycles. Each sample was evaluated for its abrasion resistance after every five laundering cycles.

\section{Results and discussion}

The collected data was analyzed through Statistical Package for Social Sciences (SPSS). Mean values and Standard Deviation was calculated. The data was collected on repeated observations of 0,5 , 10 and 15 intervals of washing. ANOVA (Repeated Measurement Analysis of Variance) was used to determine the difference between samples. P-value $\leq$ 0.05 was taken as significant.

In abrasion, breaking point is of great importance. It may be the loss of pile, loss in mass, loss in strength, color loss, appearance of a hole or rupture of yarns. This assessment is usually based on subjective analysis done through visual examination, leads to an objective analysis through numerical assessment such as Martindale abrasion tester [17]. It has been observed from (Table 2) that each sample has reduced its mass after each washing interval. Moreover, this reduction has also been seen after every interval of abrasion cycle. Wear affects the behavior and performance of fabrics in terms of their durability and performance. One of the possible reasons of poor behavior is due to the breakage of component fibers in a fabric usually caused by bending, rubbing, wear, tear and laundering procedures [18].

Table 2. Mass loss (\%age) of samples after various rubbing cycles

\begin{tabular}{|c|c|c|c|c|c|c|c|c|}
\hline $\begin{array}{l}\text { Wash } \\
\text { cycle }\end{array}$ & $\begin{array}{c}\text { Weave } \\
\text { Type }\end{array}$ & & \multicolumn{2}{c|}{$\begin{array}{c}\text { Mass loss \%age } \\
(\mathbf{1 0 0 0} \text { cycles) }\end{array}$} & \multicolumn{2}{c|}{$\begin{array}{c}\text { Mass loss \%age } \\
(\mathbf{2 0 0 0} \text { cycles) }\end{array}$} & \multicolumn{2}{c|}{$\begin{array}{c}\text { Mass loss \%age } \\
\text { (3000 cycles) }\end{array}$} \\
\hline & & $\mathrm{N}$ & Mean & SD & Mean & SD & Mean & SD \\
\hline 0 & Plain & 3 & 1.75 & 1.21 & 2.05 & 1.32 & 2.77 & 1.01 \\
\hline 0 & Twill & 3 & 3.98 & 1.56 & 4.10 & 1.25 & 4.84 & 1.52 \\
\hline 0 & Satin & 3 & 4.58 & 2.10 & 5.21 & 1.65 & 5.97 & 2.31 \\
\hline 5 & Plain & 3 & 1.85 & 1.65 & 2.09 & 1.25 & 2.92 & 1.25 \\
\hline 5 & Twill & 3 & 4.25 & 1.15 & 4.98 & 1.32 & 5.23 & 1.02 \\
\hline 5 & Satin & 3 & 5.57 & 2.15 & 6.18 & 2.34 & 6.78 & 1.05 \\
\hline 10 & Plain & 3 & 2.15 & 1.89 & 2.63 & 2.15 & 2.95 & 1.45 \\
\hline 10 & Twill & 3 & 5.32 & 1.65 & 5.86 & 1.65 & 6.13 & 1.02 \\
\hline 10 & Satin & 3 & 6.15 & 1.29 & 6.98 & 1.89 & 7.24 & 1.08 \\
\hline 15 & Plain & 3 & 2.89 & 1.05 & 3.02 & 1.45 & 3.98 & 1.04 \\
\hline 15 & Twill & 3 & 5.55 & 2.01 & 5.78 & 1.54 & 6.89 & 1.06 \\
\hline 15 & Satin & 3 & 6.59 & 1.98 & 7.18 & 1.68 & 7.95 & 1.09 \\
\hline
\end{tabular}


Fabrics have reduced their abrasive strength. Out of theses, plain weave showed less loss in mass followed by twill and satin weave patterns. One of the reasons of good abrasive strength of plain weave is the yarn structure and its interlacing pattern. It is due to the reason that yarns cling tightly to each other and presents a compact look to the fabric. Plain woven structure supports resistance against abrasion of tested fabrics. There are small floats used in plain interlacing pattern thus present small contact surface to the fabrics [10]. It provides large number of interlacements, therefore gives more cohesion to the fibers and avoid yarn slippage. So that's why, it is considered as the strongest weave among all. It is made with $1 / 1$ pattern; one harness up and one down. This pattern makes a compact surface and provides cohesion to the end product. [19]. It has been observed changes in luster and brightness of observed samples of woven fabric before and after their abrasive cycles. It was concluded that after abrasion, samples became flat and smooth and their brightness was changed due to the color loss from the surface. Yarns were suppressed due to pressure and making alterations in the light reflection and absorption at specific points. The resultant fabric appeared in combination of light and dark tones throughout its vertical length [20].

Table 3 depicts that there is a significant difference among samples made with twill and satin weave as the p-value was 0.01 and 0.00 respectively at 1000,2000 and 3000 rubbing cycles after $0,5,10$ and 15 washes. Whereas, there is an insignificant difference among samples manufactured by following plain interlacing pattern as $\mathrm{p}$ value is greater than 0.05 . It can be said that less number of interlacing helped to provide strength to the woven fabric. Plain interlacing pattern of construction is better able to make fabric strong in terms of tensile and abrasion. It was due to the reason that yarns are closely packed to each other. They make a dense cover and provide protection to the substrate (Table 3 ).

Table 3. Tests of within-subjects contrasts at various rubbing cycles

\begin{tabular}{|c|c|c|c|c|}
\hline Different washes & Rubbing Cycles & Mean Square & F & p-value \\
\hline Linear & 1000 & 45.218 & 53.452 & 0.09 \\
\hline Linear & 2000 & 41.235 & 25.612 & 0.01 \\
\hline Linear & 3000 & 43.267 & 39.129 & 0.00 \\
\hline
\end{tabular}

On the other hand, long floats are more prone to abrasion such as in the case of satin weave. There are more chances of yarn slippage with long floats as well. [21]. Uneven yarns are low in their abrasive strength due to their thick and thin regions. These irregularities make the fabric weak and unable to bear the pressure of abrasion. [22]. Coarse yarns are supposed to be low in their abrasive strength than fine yarns. Because these yarns are weak in nature and unable to resist any external pressure. Their surface is not smooth, they do not help to constitute strong base thus low in quality [23].

With an increase in laundering cycles, the mass of tested samples was reduced due to vigorous rubbing in the washing machine.
The lint collected on the upper surface of fabrics was removed during washing and making the fabric thin in appearance and usage thus deteriorate the quality [24]. Moreover, poor finishes applied on the surface of fabrics are washed away easily with any type of rubbing action such as washing, spinning, rinsing, squeezing or drying [25]. Coating in the form of textile finishes assist in making fabric abrasion resistant. It gives excellent safety against rubbing action occurred while sitting or working. It was observed that textile lamination can help to provide protection against abrasion to the fabric up to 10,000 rubbing cycles, whereas, 20,000 cycles created slight change in the brightness and smoothness of fabrics. Moreover, a 
difference in the dyed fabrics is more prominent as compared to the undyed materials. [26]. Abrasion removes the dye from the surface of fabrics, light colors fade away easily and dark tones turn into light one with every rubbing cycle. Thus making it an unpleasant in appearance. This can be controlled by using adequate type of dye on right type of material, as the dye adheres to the fibers strongly and can help to resist rubbing. [27].

\section{Conclusion}

Weaving is one of the most common fabric construction technique used all over the world. The type of weave identifies the performance of fabrics in terms of their tensile strength, abrasive strength, flexibility, extensibility, appearance and overall look. This study concludes that plain weave is the strongest among other tested weave structures. The less number of interlacings assist in making the fabric compact and strong. Plain weave structure had insignificantly affected by washing and abrasion cycles. On the other hand, twill and satin weaves had significantly reduced their mass after each cycle of abrasion and washing. This study can serve as a tool to formulate a framework for the textile and garment manufactures to produce their end products by focusing on the type of weave structure.

\section{Authors' contributions}

Conceived and designed the experiments: M Ijaz \& M Maqsood, Performed the experiments: $M$ Ijaz \& $M$ Maqsood, Analyzed the data: M Iaz \& N Sahar, Contributed materials/ analysis/ tools: $\mathrm{M}$ Maqsood \& N. Sahar, Wrote the paper: M Ijaz \& N Sahar.

\section{References}

1. Frydrych I, Dziworska G \& Matusiak M (2000). Influence of yarn properties on the strength properties of plain fabrics. Fibr Tex East Eur 8(2): 42-45.

2. Gabrijelcic H, Cernosa E \& Dimitrovski K (2008). Influence of weave and weft characteristics on tensile properties of fabrics. Fibr Tex East Eur 2(67): 45-51.
3. Das S (2010). Recycling and life cycle issues for lightweight vehicles. In Materials, Design and Manufacturing for Lightweight Vehicles. pp 309-331.

4. Alias AH, Tahir PM, Abdan K, Salit MS, Wahab MS, Berkalp OB \& Lee SH (2018). Effect of Fabric Count and Weave Design on the Properties of Hybrid Fabric Kenaf-Carbon Reinforced Laminated Epoxy Composites. Polymers 10(1): 13201051

5. Sondhelm WS (2000). Technical fabric structures-1. Woven fabrics. In Horrocks, AR \& Anand SC (Eds). Handbook of technical textiles. Cambridge: Woodhead publishing limited. pp 62-95

6. Jahan I (2017). Effect of fabric structure on the mechanical properties of woven fabrics. Adv Res in Tex Eng 2(2): 1018-1022.

7. Mayer-Gall T, Gutmann JS, \& Textor $T$ (2018). New method for damage assessment in Martindale abrasion testing. Melliand Int 1(1): 36-38.

8. Abdullah I, Blackburn RS, Russell SJ \& Taylor J (2006). Abrasion phenomena in twill tencel fabric. $J$ App Poly Sci 102(2): 1391-1398.

9. Brown R (2006). Physical testing of rubber. United States: Springer.

10. Radmanovac N, Cirkovic N, \& Sarac (2017). The importance of the resistance to wear in the choice of fabrics for protective garments. $A d v$ Tech J 6(1): 81-87.

11. Can Y \& Akaydin M (2013). Effects of laundering process on abrasion and wrinkle resistance of cotton plain fabric. J Tex Appl 23(1).

12. Ozdil N, Kayseri GO, \& Menguç GS (2012). Analysis of abrasion characteristics in textiles. Abr Res Mat 1(1): 119-46.

13. ASTM International (2010). ASTM G65. Standard test method for measuring abrasion using the dry sand/rubber wheel apparatus. West Conshohocken, PA: ASTM 
International. Retrieved from http://www.astm.org/Standards/G65.ht $\mathrm{m}$

14. ASTM International (2004). ASTM D4966-98. Standard test method for abrasion resistance of textile fabrics (Martindale abrasion tester method) .West Conshohocken, PA: ASTM International. Retrieved from http://www.astm.org/DATABASE.CA RT/HISTORICAL/D4966-98R04.htm

15. ASTM International (2010). ASTM D1776 Standard practice for conditioning and testing textiles. West Conshohocken, PA: ASTM International.

16. AATCC (2013). Monograph M6. Standardization of home laundry test conditions. American Association of Textile Chemists and Colorists. Retrieved from www.aatcc.org/testing/supplies/docs/2 05-M06.pdf

17. Jasinska I (2019). The Algorithms of Image Processing and Analysis in the Textile Fabrics Abrasion Assessment. App Sci 9(18): 3791-3805.

18. Kaynak HK \& Topalbekiroglu M (2008). Influence of fabric pattern on the abrasion resistance property of woven fabrics. Fibr Tex East Eur 16(1): 66-72.

19. Amin $R$ \& Haque $M$ (2011). Effect of Weave Structure on Fabric Properties. Anna Uni Oradea 12(5): 161-165.

20. Naderpour F, Mirjalili SA \& Sharzehee M (2009). The investigation on the influence of DMDHEU on the wrinkle and abrasion resistance of cotton fabrics using image processing. Tex Res J 79(17): 1571-1577.

21. Miranda DD (2011). An evaluation of hemp fiber for furnishing applications (Doctoral Thesis) Colorado State University.

22. Pant S \& Gupta M (2010). A study on abrasion resistance of khadi. Fiber2fashion. Retrieved from http://www.fibre2fashion.com/industr y-article/29/2821/a-study-on-abrasionresistance-of-khadil.asp

23. Kalaoglu F, Onder E \& Ozipek B (2003). Influence of varying structural parameters on abrasion characteristics of 50/50 wool/polyester blended fabrics. Tex Res J 73(11): 980-984.

24. Ijaz M, Kalsoom S \& Akthar NA (2016). Abrasion resistance of materials used for chemical protective clothing at various washing intervals. Sci Int J 28(1): 411-414

25. Ijaz M, Kalsoom S \& Akthar NA (2019). Effect of Laundering on Tensile Strength of Chemical Protective Clothing Materials. Tech J 24(01): 63-68

26. Sular V \& Bulut Y (2011). Effects of process parameters on mechanical properties of coated fabrics. International Journal of Clothing Science and Technol 23(4): 205-221.

27. Sun D \& Broman T (2017). Investigation into Abrasion Resistance of Dyed Fabrics made of Recycled and Standard Cotton Fibres. J Tex Eng Fash Tech 1(1): 6-10. 